\title{
The Six Dimensions of Child Welfare Employees' Occupational Well-Being
}

\section{Andreas Baldschun'}

Junior Research Fellow in Social Work, Department of Social Sciences, University of Eastern Finland

\begin{abstract}
The objective of this paper is the creation of a multidimensional model of occupational well-being for child welfare professions and the definition of the model's six dimensions of well-being: affective, social, cognitive, professional, personal, and psychosocial well-being. Previous concepts that were used to describe child welfare employees' well-being at work focused, primarily, on single aspects of work-related mental distress or well-being, disregarding the complexity of well-being in child welfare professions. The model presented here is based on an analysis of theoretical concepts and empirical studies addressing child welfare workers' mental distress and well-being. The body of variables, consisting of individual and organizational factors and gathered from the analysis, is used to create a positively oriented model. The key processes in developing psychological distress, as well as employee well-being, are seen in worker-client relationships and the interactions of organizations with their employees. The presented model reveals the importance of constructive interaction between organizations and employees concerning the creation and maintenance of occupational well-being. Application of the model will contribute to the enhancement of the occupational well-being of child welfare employees and, thereby, of organizational well-being. Additional investigations are needed for the empirical validation of the model.
\end{abstract}

\section{KEY WORDS}

Child welfare / concept analysis / employee well-being / mental distress / multidimensional model I occupational well-being / social work

\section{Introduction}

ue to increasing sick leave and turnover rates, work-related well-being is a current topic in the social work profession, particularly in the fields of child welfare and child protection (e.g., Collins 2008; van Hook \& Rothenberg 2009). The reasons for diminished well-being are frequently discussed in terms of high caseloads, lack of staff, and a general change in work demands. However, the occupational well-being of child welfare employees is a very complex construct and can be best explained in a multidimensional model. Such a model is still missing and this study is aiming on the creation of a six-dimensional model taking into account the specific conditions of child welfare professions. In order to get more detailed information on the occupational wellbeing of child welfare professionals, the multidimensional model of the occupational well-being of teachers developed by van Horn and colleagues (2004), encompassing

\footnotetext{
${ }^{1}$ Andreas Baldschun, Department of Social Sciences, University of Eastern Finland, PO-BOX 1627, 70211 Kuopio, Finland, E-mail: Andreas.Baldschun@uef.fi
} 
the social, cognitive, affective, personal, professional, and psychosomatic dimensions, is here further developed by adding the personal well-being dimension and was redefined to the context of child welfare professions. The additional dimension enables the integration of variables outside the workplace, such as family support or self-care in the model on an independent dimension. The structure of the model is based on variables gathered from the analysis of literature dealing with key concepts of work-related mental distress, including burnout syndrome, compassion fatigue (CF), countertransference (CT), vicarious trauma, traumatic stress, secondary traumatic stress and occupational stress syndrome, and concepts of work-related well-being, including job engagement, job satisfaction, compassion satisfaction, job demands-resources model, job crafting, and occupational well-being model.

Occupational well-being is influenced by a number of variables in several dimensions, and the avenues for developing and maintaining employee well-being are manifold. Various concepts are used in describing the vulnerability of child welfare employees to developing mental distress, and others focus on positive descriptions of work-related well-being. Although they have different orientations, the concepts have in common that they focus on single aspects of distress or well-being, disregarding the complexity of occupational well-being in child welfare professions. The model presented in this article is particularly constructed for child welfare professions, taking into account their special work conditions and demands and their impact on the different dimensions. Taking into consideration the characteristic work environment, work demands, and aims of child welfare professions, the main fields of research are the nature of child welfare work, the emotionally demanding worker-client interaction, and the interaction between employees and the organization. The underlying processes in these fields are the main sources of both mental distress and well-being in child welfare professions, and within these fields, it is possible to identify the processes and variables contributing to the occupational well-being of child welfare employees. This model is based on a positive view on work-related well-being and is focusing on protecting and supporting factors instead of the symptoms of mental distress and contributes to a deeper understanding of the occupational well-being of child welfare professionals. The next chapter provides an overview of the key concepts used for the concept analysis followed by describing the methodology applied in the study. Then, the findings of the concept analysis are presented in the results chapter continuing with the construction of the six-dimensional model. The article is being concluded with a discussion on the topic and by bringing up further implications.

\section{Overview of the key concepts of work-related mental distress and well-being}

From the literature, two groups of concepts were identified: concepts of work-related mental distress and concepts of work-related well-being. The difference between the concepts is found in their basic orientation toward either negative or positive outcomes. Whereas concepts of mental distress focus on symptoms and consequences for employees and organizations, the concepts of well-being reveal the factors which lead to higher levels of well-being and better performance outcomes. Probably the most common concept used to describe work-related distress is the burnout syndrome. Burnout, caused 
by a response to chronic emotional and interpersonal stressors on the job, represents a serious concern in the social work profession (Gillespie 1986; Söderfeld et al. 1995). Burnout-related job characteristics are quantitative job demands, such as workload and time pressure, and qualitative job demands, such as role conflict and role ambiguity (Decker et al. 2002). Additionally, the absence of job resources, such as social support, participation in decision-making, and job autonomy, is correlated with burnout. Occupational characteristics are related to "the emotional challenges of working intensively with other people" (Maslach et al. 2001, pp. 407-408).

Another group of concepts describing the vulnerability of child welfare employees to mental distress consists of compassion fatigue, countertransference, vicarious trauma, traumatic stress, and secondary traumatic stress. The term CF is defined as "the professional or care-giver's reduced capacity or interest in being empathic to client situations" (Dill 2007, p. 183). Radey and Figley (2007, p. 207) understand CF as "a direct result of exposure to client suffering." Work-related emotional overload, related to staff-client interaction, represents the major risk of developing CF (Dill 2007; Sprang et al. 2007). The concept of CT refers to emotional reactions to present work experiences, triggered by the social worker's past life experiences (Kanter 2007). According to Figley (2002, p. 1436), CT differs from CF in its "chronic attachment, associated with family of origin relationships," and it is not related to the worker's empathy toward the client's trauma. That is to say that harmful childhood experiences of the worker are the reason for the emotional distress caused by the current work with children and families. The concept of vicarious trauma describes the negative impact of work with traumatized clients in a cumulative process, which can lead to changes in self- and professional identity (Agass 2002; Bride et al. 2007a, 2007b; Dill 2007).

In addition, the conceptions of traumatic stress and secondary traumatic stress are associated with the well-being of child welfare workers. According to Horwitz (1998, p. 365), trauma can occur among child welfare employees, "when a caseload event or series of events is beyond the capacity of the social worker to manage." Horwitz differentiates direct and indirect trauma experienced by the social worker and caused by the work with clients. The concept of secondary traumatic stress occurs when the social worker is closely touched by the clients' trauma, which differs from the trauma conception in that the social worker is not experiencing a trauma himself or herself (Bride et al. 2007a; Dill 2007; Kanter 2007; Sprang et al. 2007). The authors of the various studies refer to a personal trauma history as a significant risk factor to develop a secondary trauma stress syndrome. They mention social support and positive coping strategies as important preventive interventions. The occupational stress syndrome represents another concept, which is used to explain absenteeism and high turnover rates among child welfare workers (Coffey et al. 2004; Nissly et al. 2005). Farmer and colleagues (1984) distinguish personal and occupational stress factors, which can lead to negative physiological and emotional effects. Chronic personal and occupational stress conditions may result in behavioral reactions, such as argumentativeness and fighting, withdrawal, refusal to socialize, and overdependence. Social support is seen as the most effective mitigation against negative outcomes in all forms of job-related stressors (Collins 2008; Farmer et al. 1984; Nissly et al. 2005).

The above-mentioned concepts deal with negative outcomes for child welfare workers caused by the work with children and families. Recently, research has concentrated more on a positive description of occupational well-being and brought out concepts, 
such as compassion satisfaction, job satisfaction, job engagement, job demands-resources model, job crafting, and occupational well-being model. The concept of compassion satisfaction has been found to be positively associated with reduced levels of CF and burnout (Conrad \& Kellar-Guenther 2006; van Hook \& Rothenberg 2009). Radey and Figley (2007) point out the importance of affect, work resources, and self-care for the well-being of child welfare workers. Employees obtain pleasure from helping and experience good feelings, resulting from the ability to help score high in compassion satisfaction (Conrad \& Kellar-Guenther 2006; van Hook \& Rothenberg 2009). Rauktis and Koeske (1994) describe job satisfaction as a multidimensional construct, based on intrinsic, extrinsic, and organizational dimensions. Further, Koeske and colleagues (1994) point out that job satisfaction is strongly related to structural factors, such as autonomy and bureaucratization. Acquavita and colleagues (2009) and Collins (2008) have found that social workers, in particular, show a high intrinsic job satisfaction, which is based on a high commitment to their work. Besides these intrinsic factors, organizational factors and job demands also play a role in job satisfaction (Acquavita et al. 2009). Elpers and Westhuis (2008) emphasize the importance of organizational leadership as a key factor for the job satisfaction of employees.

The concept of job engagement represents an approach which emphasizes the positive role of the well-being of child welfare workers, underlying two dimensions of work-related well-being, namely activation and identification (Schaufeli et al. 2002). Job engagement focuses on human strengths and optimal functioning, instead of on weaknesses and malfunctioning. The authors present a three-factor structure of engagement, including vigor, dedication, and absorption, and efficacy is seen as another important element of engagement (Schaufeli et al. 2002). Several studies show that work engagement can be facilitated by personal resources and job resources (Bakker et al. 2011). The job demands-resources model is focusing on the balance between job demands and resources. Job demands are described as physical, psychological, social, and organizational aspects of the work that require certain skills and efforts to deal with. Job resources encompass these skills and efforts, which enable employees to handle the job demands in such a way that they do not cause any harm, but lead to efficacy and high-quality performance (Bakker et al. 2003).

Furthermore, job crafting is an empowering concept, aiming at shaping work tasks and cognitive boundaries (Wrzesniewski \& Dutton 2001). The concept describes a technique for changing the nature of the work into more meaningful tasks. This can be done concretely, by altering job tasks and the nature of interaction at work, or cognitively, by altering one's view of the work tasks (Berg et al. 2010). The idea of job crafting is strongly related to job autonomy, which is seen as an important factor in achieving occupational well-being (de Jonge \& Schaufeli 1998; van Horn et al. 2004). A concept of occupational well-being particularly constructed for the teaching profession is presented by van Horn and colleagues (2004) as a multidimensional model consisting of the social, affective, cognitive, professional, and psychosomatic dimensions. The authors emphasize the multidimensionality of work-related well-being and draw on several models used to describe well-being in different contexts. Also, the model is relatively wideranging; it takes no account of influencing variables outside the work environment, such as personality traits, demographic variables, and the work-family interface. However, the study, generally, confirms occupational well-being as a case of multidimensional phenomena and, therein, the development of the occupational well-being model for child 
welfare professions presented in this article builds on the studies' conceptualization of occupational well-being.

\section{Method}

One main task was the identification of the variables explaining the occupational wellbeing of child welfare professions. The determination of the sources of work-related mental distress and well-being, as well as the associated concepts, was followed by the identification of the literature explaining the phenomena, either theoretically or empirically. A social science database set containing 10 preset databases (see Table 1) was used to search for texts and studies contributing best to explain the concepts. As keywords, "child welfare," "child protection," "employee well-being," "mental distress," "occupational well-being," "social work," and the names of the concepts listed in Table 1 were used separately and in combination with each other for information retrieval. A certain timeframe was not set, as it was focused on publications contributing best to the purpose of this investigation. Altogether, 104 publications were selected, of which 50 were selected for the purpose of the analysis. The criteria for selection were that, on the one hand, the publications were theoretical descriptions of one of the concepts or, on the other hand, that they were empirical studies on mental distress and well-being carried out in the field of social work and, particularly, in the field of child welfare and child protection. Attention was paid to papers describing the structure of the respective phenomena and the outcomes for individuals and organizations. Further, it was important to reveal information about sources of distress and of well-being, as well as to identify the preventing and supporting factors. Papers reviewing the literature, focusing on measurement issues and studies undertaken in a special or regional context did not qualify for the analysis, as those could not contribute to the purpose of this analysis.

Table I Social science database set.

- Arts \& Humanities Citation Index (ISI)

- Business Source Elite (EBSCO)

- EBSCOhost Academic Search Premier

- Emerald Journals (Emerald)

- JSTOR Arts \& Sciences I Collection

- ScienceDirect (Elsevier)

- Social Sciences Citation Index (ISI)

- Social Services Abstracts (ProQuest)

- SocINDEX with Full Text (EBSCO)

- Sociological Abstracts (ProQuest) 
Additional information was drawn from literature dealing with the aspects of relationship-based practice, which represents a basic element of the nature of social work and child welfare (e.g., Ruch et al. 2010; Sudbery 2002). The publications contributed to the creation of the model presented in this article by adding variables related to the specific job demands in the field and by identifying contributing factors to occupational well-being. In order to determine the variables for the creation of the multidimensional model of occupational well-being for child welfare employees, the key concepts dealing with work-related distress and well-being were analyzed, using the systematic concept analysis method developed by Nuopponen (2011). The method comprises various options for the planned task and includes a set of tools for facilitating a structured concept analysis. These are the "satellite model" for the general structure of the analysis, and a set of eight concept relation models for the detailed analysis. From these options, the "causation model" and the "dependency model" were chosen as being appropriate for the purpose of this study.

\section{Results of the concept analysis}

The literature dealing with the main concepts of the mental distress and well-being of child welfare workers was examined in order to identify a body of variables seen as relevant to explain the occupational well-being for child welfare professions. In Table 2, the key concepts describing the mental distress and well-being of child welfare workers are listed, including references of the selected literature used in the analysis. All the concepts refer to situations in work life, where the employee is exposed to face-to-face work with clients and to organizational work demands. The concepts of work-related distress address the negative outcomes of the emotionally demanding work with clients. Each of the concepts focuses on specific situations in the work life, which lead to different symptoms in employees. However, the concepts are connected to each other through their affiliation with the employees' emotional, physical, and psychosocial health, which could be identified as the main vulnerable areas for work-related distress.

In contrast, the concepts of work-related well-being do not focus on negative outcomes and symptoms, but on positive descriptions of certain aspects of the work life of employees. The main idea of these concepts is to describe the conditions needed to gain a maximum of work-related satisfaction and mental health. As mentioned for the concepts of distress, the concepts of work-related well-being also refer to the emotional part of the work with clients and the work demands predefined by the organization. All the concepts describe individual, as well as organizational, factors responsible for the outcomes, either negative or positive. However, they all have in common that they focus on a single aspect, disregarding the complexity of the occupational well-being of child welfare employees.

One result of the analysis was the identification of the items describing either the problems derived from or the solutions to the phenomena of the concepts. These items were then clustered and categorized into variables which, on the one hand, can be associated with specific tasks or areas of the work environment and, on the other hand, can be used to create factors for describing occupational well-being. Table 3 shows the revealed preventing and supporting factors. Whereas the preventing factors are mainly used in negatively oriented concepts of work-related mental distress, which focus on 
Table II Overview of concepts and related literature.

Concepts of work-related mental distress
Burnout syndrome:
Freudenberger 1974; Maslach \& Jackson 1981;
Gillespie 1986; Söderfeld et al. I995; Decker et al.
2002; Maslach et al. 200 I; McCarter 2007

\section{Compassion fatigue:}

Figley 2002; Nelson-Gardell \& Harris 2003;

Conrad \& Kellar-Guenther 2006; Sprang et al. 2007;

Dill 2007; Radey \& Figley 2007; Kanter 2007

\section{Countertransference:}

Agass 2002; Figley 2002; Kanter 2007

\section{Traumatic stress and secondary traumatic stress:}

Horwitz 1998; Figley 2002; Nelson-Gardell \& Harris 2003; Bride et al. 2007a; Kanter 2007; Sprang et al. 2007; Dill 2007; Knight 2010

\section{Vicarious trauma:}

Sexton 1999; Nelson-Gardell \& Harris 2003; Bride et al. 2007a, 2007b; Dill 2007; Knight 2010; Napoli \& Bonifas 201।

\section{Occupational stress syndrome:}

Farmer et al. 1984; Bradley \& Sutherland 1995; Coffey et al. 2004; Nissly et al. 2005; Collins 2008

\section{Concepts of work-related well-being} Job engagement:

de Jonge \& Schaufeli 1998; Schaufeli et al. 2002; Schaufeli \& Bakker 2003; Bakker et al. 20I I

\section{Job satisfaction:}

Rauktis \& Koeske 1994; Winfield \& Barlow 1995 Koeske et al. 1994; Ulrich et al. 2007; Elpers \& Westhuis 2008; Collins 2008; Rossrucker 2008; Acquavita et al. 2009

\section{Compassion satisfaction:}

Conrad \& Kellar-Guenther 2006; Radey \& Figley 2007; Sprang et al. 2007; van Hook \& Rothenberg 2009

\section{Job demands-resources model:}

Demerouti et al. 200 I; Schaufeli \& Bakker 2004; Bakker \& Demerouti 2007; Lizano \& Mor Barak 2012

\section{Job crafting:}

Wrzesniewski \& Dutton 200।; Berg et al. 20 I0; Tims et al. 2012

\section{Occupational well-being:}

van Horn et al. 2004

Table III Preventing and supporting factors.

\begin{tabular}{|c|c|c|}
\hline & $\begin{array}{l}\text { Work-related mental distress } \\
\text { preventing factors }\end{array}$ & $\begin{array}{l}\text { Work-related well-being } \\
\text { supporting factors }\end{array}$ \\
\hline Organizational factors & $\begin{array}{l}\text { - decreased caseload size } \\
\text { - job demand evaluation } \\
\text { - job-related trainings } \\
\text { - promotion and estimation } \\
\text { - reduced organizational constraints } \\
\text { - social support from peers and } \\
\text { - organization } \\
\text { - supervision }\end{array}$ & $\begin{array}{l}\text { - balance of job autonomy } \\
\text { - leadership style } \\
\text { - social support from peers and } \\
\text { organization } \\
\text { - supervision } \\
\text { - supportive work environment } \\
\text { - validation of performance } \\
\text { - work resources }\end{array}$ \\
\hline Individual factors & $\begin{array}{l}\text { - } \text { age } \\
\text { - competences } \\
\text { - education and training } \\
\text { - emotional strength } \\
\text { - positive coping strategies } \\
\text { - resilience } \\
\text { - work experience }\end{array}$ & $\begin{array}{l}\text { - appropriate social areas } \\
\text { - cognitive skills } \\
\text { - competence } \\
\text { - job-related calmness } \\
\text { - self-care } \\
\text { - self-efficacy } \\
\text { - vigor }\end{array}$ \\
\hline
\end{tabular}


negative symptoms and outcomes caused by the sources of stress, the supporting factors can be found in the positively oriented concepts of work-related well-being. The idea of supporting factors is used to describe the promoting circumstances, which lead to employee well-being. Although the factors revealed in both the symptom-oriented and the well-being-oriented concepts are basically the same, the table shows the differences in the basic orientation of the concepts. Whereas the concepts of work-related distress try to prevent symptoms from developing in employees, the concepts of work-related well-being focus on the support of well-being.

Another distinction among the factors can be made between individual and organizational factors. Individual factors are associated with variables, which can be influenced, mainly, by the individual, although they might depend to some extent on the work environment and the support offered by the organization. Some of the individual variables refer to the personality of the person and can, hardly, be learned or trained, and others are related to vocational training, which are, usually, acquired before the labor market is entered. Some of these skills, however, can be strengthened through training during work life or can be developed through work experience and job-related support. The organizational factors result from statutory provisions, depending on the function of the organization, the organizational structure, and the decisions of the authorities, who have the power to define the work environment and work performance processes. Although some of the influencing factors are predefined by policies and organizational constraints, most of the factors leave sufficient leeway for modification. Together, the individual and the organizational factors are defined through variables, which are needed to explain the occupational well-being of child welfare professionals. In the next section, these factors and variables are associated with particular dimensions of well-being, in order to construct the occupational well-being model.

\section{Construction of the occupational well-being model}

The above-described concepts provide a comprehensive basis for the occupational wellbeing model created in this section. The factors and variables drawn from the concepts are used to define the dimensions of occupational well-being for child welfare professions and to allocate them to the respective dimensions. The model of occupational well-being for the child welfare profession presented in this article encompasses the six dimensions of affective, social, cognitive, professional, personal, and psychosomatic well-being (see Figure 1). For this purpose, the occupational well-being model for teachers, developed by van Horn and colleagues (2004), provide the basis for the model presented in this article. Their study, however, focused on the teaching profession and is limited for use among teachers, which makes a generalization to child welfare professions problematic (van Horn et al. 2004, pp. 372-373). Compared with social and child welfare professions, the teaching profession has a different nature and consists of variables, which cannot be, generally, applied to child welfare professions. Besides the overlapping of some characteristics of the nature of the professions, such as face-to-face-contact, target group children, or the come-structure, major differences in the professions are seen among others in the basic aim and task of the work and the decision-making authority of social workers. 
Figure I: Occupational well-being model for child welfare professions

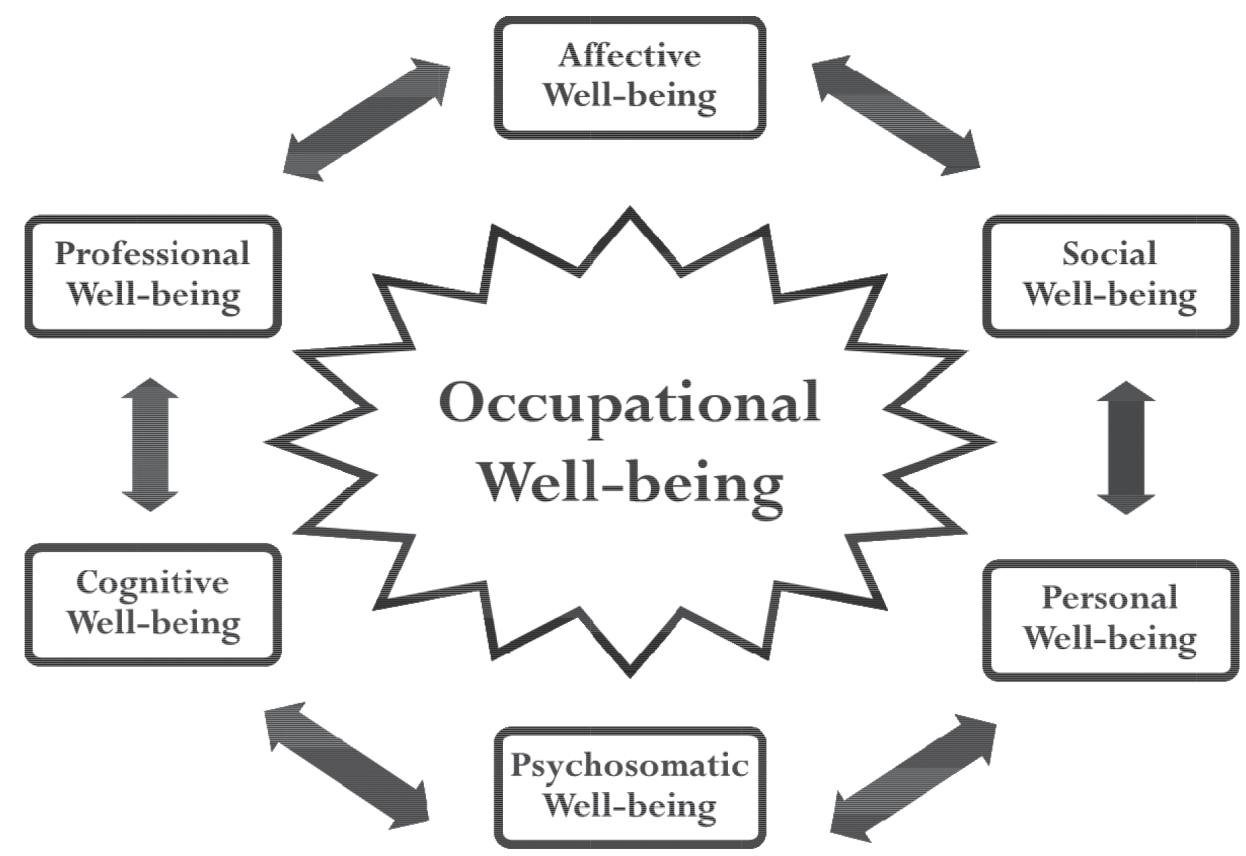

Additionally, in this study the model has been further developed by adding the personal well-being dimension, taking into account the evidence from theory and practice on the impact of support from family and friends, personality traits, and demographic factors on the employees' occupational well-being (e.g., Danna \& Griffin 1999; Siebert 2005; van Steenbergen \& Ellemers 2009). The allocation of personal variables on a separate dimension enables the description of the occupational well-being among child welfare workers in more detail. These aspects have been underrepresented in the initial model by van Horn and colleagues (2004). Therefore, it is essential to redefine the dimensions, according to the needs and demands of child welfare work, using the variables that prevent mental distress and support occupational well-being in the field. Particularly, the information regarding the preventive and supportive factors, as well as the knowledge of the causes of negative outcomes, is taken into consideration. The sources of mental distress and well-being are integrated into the proposed model, in order to define the resources and needs of employees, as well as of the organizations.

Individually, the concepts do not show the whole picture of the well-being of child welfare workers in all its complexity. Nevertheless, they are all related to the nature of child welfare work with clients in difficult situations. The worker-client relationship is the main source of employees' distress, as well as of their satisfaction, and besides individual factors, the work environment and the interaction between employees and the organization play an essential role in developing and maintaining the occupational wellbeing of employees (e.g., Guest \& Conway 2009; Nelson \& Simmons 2011, pp. 67-68). 
Therefore, it is necessary to bring together all the relevant aspects and dimensions of the well-being of employees. Occupational well-being, in the context of child welfare work, is understood in terms of psychosocial, emotional, and physical health, characterized by job satisfaction (or even more job engagement), compassion satisfaction, and self-efficacy. Further, employee well-being is closely related to high performance and client outcomes and has a strong correlation with organizational well-being (Tinline \& Moss 2009).

\section{Affective well-being dimension}

Due to the nature of child welfare work, the affective dimension plays a central role in the well-being of child welfare employees. Difficult and burdening life situations are unavoidable and must be dealt with frequently. Affective well-being refers to an emotional state characterized by emotional strength, vigor, job-related calmness, and affective satisfaction (Daniels 2000; van Horn et al. 2004). Emotional strength refers to the ability to cope with the experience of the difficult life situations of clients, to identify the source of one's emotions triggered by the work situation, and to recover from difficult experiences. It also requires reflecting on the worker's own life experience with his or her family of origin and the ability to distinguish between one's own harmful emotions and those of the client. Showing empathy and understanding of a client's situation, while keeping a professional distance, requires a high level of professionalism. Vigor contributes to affective well-being by its quality of continuously adding energy into the affective system, in order to cope with burdening situations. Further, the empowering nature of vigor helps in overcoming difficult situations. Job-related calmness is the opposite of job-related anxiety. Whereas job-related anxiety refers to burdens in working life and to a serious decrease in affective well-being, job-related calmness is an emotional state that gives the employee self-confidence at work (de Jonge \& Schaufeli 1998, van Hook \& Rothenberg 2009). Affective satisfaction is more the result of the presence of other factors than an independent characteristic of affective well-being. It describes a state of mind where the employee's affect is functioning well enough to deal with work demands and is supported properly to avoid any harm.

Developing and maintaining affective well-being is, mainly, an individual issue, but it is also an organizational task. Every employee is responsible for reflecting on his or her own emotional weak points and finding ways to deal with them, so that they do not cause any harm in work situations. The ability to deal with such issues is a professional quality that characterizes effective workers in the field of child welfare (Agass 2002; Sudbery 2002). Nevertheless, supporting and protecting employees is also an organizational responsibility. Due to the fact that affective harms are work-related and a natural part of the process in working with clients, the work environment has to be organized in a way that provides a maximum of support to the employees. In the case of affective wellbeing among child welfare employees, social support plays an important role, including such elements as regular supervision to process critical and demanding situations, the work environment being organized in such a way that peer support is available when necessary and the availability of proper facilities for relaxation (Coffey et al. 2004; Sprang et al. 2007). Other important factors are education and specialized training. Clients with special needs require that organizations supply specialized employees in order to provide effective services, as well as supplying ways of maintaining the workforce's ability to deal 
with special demands. In particular, work with traumatized clients requires specialized training for those who have intensive interactions with them. Additionally, the serviceproviding organization has to carefully define a manageable caseload size, and validation of performance needs to be done to provide a supportive work environment.

\section{Social well-being dimension}

The workplace is where one spends the most time during one's years in the workforce. Depending on the size and function of the organization, a great deal of time is spent interacting with colleagues, superiors, and clients. Employees spend their days with likeable colleagues, as well as with those they would never spend time with voluntarily. However, one has to work together with all of one's colleagues, in order to achieve desired outcomes. This is made difficult by the fact that working with deprived persons and families with destructive behavior patterns exposes professionals to the risk of transferring those patterns into their own work environments (Agass 2002). Particularly stressful and demanding work requires a pleasant working atmosphere to enable the development of a constant level of social well-being. Further, the ability to engage in authentic behavior at work leads to higher social well-being (Farmer et al. 1984).

The creation and maintenance of functioning work relationships requires certain skills among the participants, as well as a supportive work environment. The workforce needs opportunities to build interpersonal relationships and to create a good work climate. The best way to achieve this is by providing resources for improving the atmosphere at both work-related and social events. Meetings should include enough time for professional discussions, as well as for informal but topic-related conversations. The social areas should be equipped in ways that employees prefer, and annual festivities and organizational events need to be celebrated properly. Further, the leadership style crucially influences the work atmosphere and social well-being of employees (Elpers \& Westhuis 2008; Kets de Vries et al. 2009). Here, the key issues are participation and autonomy (Kim \& Stoner 2008; Weaver et al. 2007). Whereas the participation of employees in social and work-related events enhances their identification with the workplace, job autonomy enables employees to demonstrate their individual skills and strengths. An appropriate leadership style shows esteem to the employees and supports the development of social well-being at work (Tham 2007).

\section{Cognitive well-being dimension}

The cognitive well-being dimension refers to the ability to process work demands and work-related information, in order to make functional decisions. This is important for the child welfare professional, because of the requirement to solve complex tasks. In particular, working with families and children involves the pressure to assess situations properly and make the right decisions within a limited time frame (van Hook \& Rothenberg 2009). The consequences of poor decision-making can be extensive for the employee, the service-providing organization, and the service user, which increases the pressure to find correct and comprehensible solutions. Cognitive well-being involves individual characteristics, such as quick apprehension, assessment skills, affective calmness, and the ability 
to concentrate on work tasks (Kanter 2007; van Horn et al. 2004). The majority of the characteristics are closely related to the work environment and work demands. This implies that the organization could provide supporting conditions for the workforce in order to develop and to maintain individual skills (Coffey et al. 2004). Important aspects, in that sense, are specialized training, the validation of decision-making processes, and social support, such as supervision or peer counseling. Additionally, the work environment has to provide a climate that enables employees to work with concentration, confidence, and a minimum of pressure. The key factors for this are workload size, individual and professional competences, and balanced job autonomy (e.g., Söderfeld et al. 1995).

\section{Professional well-being dimension}

This dimension again covers individual, as well as organizational, characteristics, such as competence, autonomy, efficacy, promotion, and estimation. The basic precondition for achieving professional well-being is competence related to job demands and the agency operating process (Decker et al. 2002). Comprehensive vocational education and specialized training provide a firm basis for successfully carrying out the service tasks (Schrapper 1999). Employees usually have basic skills when they begin their careers, and specialized training is often provided on the job, according to the field of activity. However, professional well-being includes more than skills and education; efficacy of the work process and of outcomes is another contributing factor. A good performance with functional outcomes leads to job satisfaction, which is another factor in professional well-being (Maslach et al. 2001). Additionally, extrinsic factors, such as salary, reputation, and promotion possibilities, contribute to high levels of professional wellbeing. Basically, two resources can be identified for the development of professional well-being: the individual role and the organizational role. On the individual side, in addition to professional competencies, the resources include engagement, motivation, self-efficacy, and achievement. On the organizational side, there are work resources, training possibilities, social support, and fair salaries. As a consequence, the individual who collaborates with his or her organization achieves the highest level of professional well-being (Demerouti et al. 2001; Radey \& Figley 2007; Tham 2007).

\section{Personal well-being dimension}

In this study, the personal well-being dimension has been added to the model for enabling the integration of variables outside the workplace. This dimension comprises individual variables, such as personality traits, demographic variables, and the homework interface. These variables might vary a great deal between individuals and can hardly be influenced by the employing organization. To personality traits belong the variables, hardiness, resilience, coping strategies, type A personality, and the locus of control (Collins 2008; Danna \& Griffin 1999; Koeske \& Kirk 1995; Maslach et al. 2001). This group of variables is related to the employee's personality and one's capability to handle work demands and coping with stress. In addition to personality traits, the workers' earlier life experience and personal history of trauma effects the subjective well-being of child welfare employees (Horwitz 1998; Siebert 2005). Those 
experiences can be triggered by clients' issues and might affect negatively on the employees' ability to act professionally and, therein, affects the overall work performance and outcome (Horwitz 1998, p. 368). By paying attention to these traits and experiences, it is possible to gain information on the employees' vulnerability to develop mental distress.

Another important factor on the personal well-being dimension is the workfamily interface. Empirical evidence reveals that the level of social support from outside the workplace and the support on combining work and family has a considerable impact on the individual's well-being and, therein, on the occupational well-being (e.g., Danna \& Griffin 1999; van Steenbergen \& Ellemers 2009). Employees recover from work in their leisure time at home with their families, friends, and hobbies, which also contributes to the subjective well-being, as well as to their working capacity. Therefore, the connectedness and interrelation of work life and family life has to be taken into account, when describing and measuring the occupational well-being. Additionally, demographic variables, such as age, gender, ethnicity, marital status, living situation, and family size, are included in the personal well-being dimension. Whereas marital status, living situation, and family size are closely related to the work-family interface, age can be associated with work experience and a general experience of life and it's preventing effects on distress. Also, a significant correlation of gender and ethnicity with occupational well-being could not be found in the literature examined for this article; these variables are included in the dimension. However, the correlation of gender and ethnicity with the job satisfaction of social workers has been examined in a study on personal and organizational diversity factors (Acquavita et al. 2009), but were found to be nonsignificant.

\section{Psychosomatic well-being dimension}

Psychosomatic well-being represents another major dimension in the presented model for the occupational well-being of child welfare workers. It covers all job-related aspects of physical, psychological, and mental health. Logically, a low level on this dimension can lead to reduced performance, absenteeism, and reduced turnover (Evans et al. 2006). Closely related to the affective well-being dimension, psychosomatic well-being is directly influenced by negative outcomes of job-related interactions with clients and is indirectly influenced by deficits in other dimensions of occupational well-being. The symptoms occurring in this dimension are manifold and often difficult to connect directly to work-related issues. Headaches, back pains, or indigestion might be caused by other factors than the work situation, but they still represent typical symptoms of work-related dysfunction, particularly if they are frequent (Koeske \& Kirk 1995). This dimension holds a central position in the concept of occupational well-being, because of its connectedness with the other dimensions. Psychosomatic well-being is a result of the successful implementation of the other dimensions and has only limited value as an independent dimension. A high level of psychosomatic well-being results from high levels of well-being related to the other four dimensions, and any deficiencies in another dimension can cause low levels in the psychosomatic dimension. Therefore, building and supporting psychosomatic well-being has an effect on all the other dimensions of occupational well-being. 


\section{Discussion}

The object of this investigation was the creation of a six-dimensional model of occupational well-being for child welfare professions. The proposed model described above differs from other models and concepts, in that it includes all the dimensions that influence job-related well-being, instead of focusing on only one aspect of the whole. Well-being, either related to an entire life situation or to one's job, develops from the presence of positive characteristics in various dimensions. This notion was already formulated in an early study by Warr and Routledge (1969), which argued that job satisfaction should be studied in separate dimensions, because of the multifaceted job characteristics. Later, Warr and colleagues (1979) found that job satisfaction and psychological well-being are associated with total life satisfaction, happiness, and low self-rated anxiety, and they referred to the holism of well-being. More recently, de Jonge and Schaufeli (1998) have drawn on the multidimensional model of mental health developed by Warr, in order to emphasize the complexity of employee well-being. These examples show that the idea of multidimensionality in research on work-related issues, such as employee well-being or job satisfaction, is well known and has, previously, been applied.

However, the idea has never been implemented using a broader view of occupational well-being for the child welfare profession. It has already been pointed out that the analyzed studies only deal with partial aspects of the whole. This approach, admittedly, gives a detailed view of one dimension at a time, but it neglects other important influences. A multidimensional model combines all relevant aspects of a construct to make use of the interrelations between the different dimensions and to synergize the effects resulting from these interactions. This is, particularly, relevant to the child welfare profession, where individual demands are interwoven with organizational demands. On the one side, child welfare workers have to deal with emotional harm caused by the work with deprived or traumatized clients, and on the other side, they have to fulfill the work tasks predefined by the organizations. Child welfare employees are the intersection between the service user and the service provider, with the task of satisfying the requirements of both sides (Dill 2007; Ruch et al. 2010). Therefore, an effective and successful cooperation between employees and the organization requires special attention and depends on multidimensional factors, which are also implemented in the proposed model.

The model developed by van Horn and colleagues (2004) represented a constructive basis to build on. However, their initial model represents a closed unit, with only limited possibilities to consider influences coming from outside the system. The additional personal well-being dimension changes the structure of occupational well-being and the interaction between the dimensions significantly. It includes external variables with a direct impact on both individual and organizational well-being. Further, the interrelations and the dynamic between the dimensions are changing. This allows a more detailed view of the occupational well-being of child welfare employees and their organizations. However, both models have in common their positive orientation on the description of occupational well-being. There is also an overlapping of several variables in the affective-, cognitive-, and psychosomatic dimension, which might be found in the transferability of these dimensions to other professions. Nevertheless, there are differences in the definition of the variables on the microlevel of the dimensions, according to the specific work environment and work demands in the different professions. The social 
and professional dimension differs significantly in both models, due to the differences in the aim and task of the work, and due to differences in the organizational hierarchy and structure.

Using the knowledge gained from the description of the occupational well-being of child welfare workers in organizational development processes may reveal the positive effects of interdependency and the synergy potential. Hereby, important aspects are the focus on the interrelations of the various dimensions and on the evaluation of the mentioned effects on child welfare employees. All six dimensions can be described and measured independently, but that would only show a fragment or a limited picture of the whole. Moreover, it would miss the interwoven elements that work together on different levels and in different dimensions. For example, elements of the professional dimension interact with elements of the cognitive or social well-being dimension, and elements of affective well-being interact with elements of the psychosocial and professional well-being. Characteristics, such as supervision, education, work demands, or job autonomy, are relevant factors in several dimensions, but they have different impacts on each dimension. This implies that by focusing on only one characteristic, a positive impact can be seen in several dimensions.

Generally, in the field of child welfare, individual and organizational factors are too interwoven to be measured and evaluated separately without losing their interrelated influence on each other. The individual needs a caring and supporting work environment, and an organization needs effective, engaged, and healthy employees. The occupational well-being of employees is a precondition for organizational well-being. This assumption fits any profession, but it has particular relevance in the child welfare profession. Here, employees need specific emotional and professional strengths that can be supported and maintained through particular elements within the work environment. According to the occupational well-being model, high levels of employee well-being can be achieved by activating all the six dimensions and by implementing preventive and supportive factors. This needs to be done through cooperation and interaction between the organization and its employees. As a result of focusing on all six dimensions equally, synergetic effects are generated, which results in much more positive outcomes than are seen when only focusing on single dimensions.

\section{Conclusions}

The occupational well-being model for child welfare professions, as presented in this paper, is based on empirical research and on findings that are mainly gathered in the fields of social work and child welfare; nevertheless, in its current state, it represents only a theoretical model. Empirical investigations are now needed for the empirical validation of the model. It needs to be clarified if the occupational well-being in child welfare professions can be sufficiently explained with the proposed six dimensions. Further, the relevance of the identified variables for the distinct dimension and for the explanation of occupational well-being among child welfare employees and organizations needs to be validated. One challenging aspect of the study will be the development of an instrument to measure occupational well-being as a multidimensional construct. On the one hand, the questionnaire should cover all the variables of the six dimensions, and on the other hand, it should be kept at a moderate length, which can be handled with appropriate time 
resources. Further studies should focus on the confirmation of the multidimensionality of occupational well-being and on a deeper understanding of the correlation of the six dimensions. Additionally, it will be interesting to gather more knowledge on the impact of any of the single variables on the different dimensions.

This paper contributes theoretically to a deeper understanding of the structure and constitution of occupational well-being in child welfare professions and displays the relevant factors influencing the well-being of employees in the field. Further, it emphasizes the importance of individual and organizational factors. It states the importance of the active interaction between employees and the organization, in order to activate the synergies in developing and maintaining occupational well-being for both the employees and the organization. The model also addresses emotionally demanding worker-client interactions and provides knowledge of the factors which influence the development of processes for dealing positively with mental distress. The resulting positive approach has innovative aspects in terms of multidimensionality, synergy, and resource orientation, instead of deficit orientation, and is solution-focused, instead of problem-focused. Through its multidimensionality, the model takes into account the demanding elements found in the worker-client relationship and in statutory requirements, but it also takes into account current influences caused by changes in work life and in society, such as the reconstruction of organizations, political changes, and changes in living situations. Those trends should continuously be taken into account while investigating in research on occupational wellbeing with a multidimensional model.

\section{References}

Acquavita, S.; Pittman, J.; Gibbons, M. \& Castellanos-Brown, K. (2009) Personal and Organizational Diversity Factors' Impact on Social Workers' Job Satisfaction: Results from a National Internet-Based Survey. Administration in Social Work, 33, 151-166. DOI: $10.1080 / 03643100902768824$

Agass, D. (2002) Countertransference, Supervision and the Reflection Process. Journal of Social Work Practice, 16(2), 125-133. DOI: 10.1080/0265053022000033694

Bakker, A.B.; Demerouti, E.; Taris, T.W.; Schaufeli, W.B. \& Schreurs, P.J.G. (2003) A Multigroup Analysis of the Job-Demands-Resources Model in Four Home Care Organizations. International Journal of Stress Management, 10(1), 16-38. DOI:10.1037/1072-5245.10.1.16

Bakker, A.B. \& Demerouti, E. (2007) The Job Demands-Resources Model: State of Art. Journal of Managerial Psychology, 22(3), 309-328. DOI:10.1108/02683940710733115

Bakker, A.B.; Albrecht, S.L. \& Leiter, M.P. (2011) Key Questions Regarding Work Engagement. European Journal of Work and Organizational Psychology, 20(1), 4-28. DOI:10. 1080/1359432X.2010.485352

Berg, J.M.; Wrzesniewski, A. \& Dutton, J.E. (2010) Perceiving and Responding to Challenges in Job Crafting at Different Ranks: When Proactivity Requires Adaptivity. Journal of Organizational Behavior, 31, 158-186. DOI:10.1002/job.645

Bradley, J. \& Sutherland, V. (1995) Occupational Stress in Social Services: A Comparison of Social Workers and Home Help Staff. British Journal of Social Work, 25, 313-331.

Bride, B.; Radey, M. \& Figley, C.R. (2007a) Measuring Compassion Fatigue. Clinical Social Work Journal, 35, 155-163. DOI: 10.1007/s10615-007-0091-7

Bride, B.; Jones, J. \& MacMaster, S. (2007b) Correlates of Secondary Traumatic Stress in Child Protective Service Workers. The Journal of Evidence-Based Social Work, 4(3/4), 69-80. DOI: 10.1300/J394v04n03_05 
Coffey, M.; Dugdill, L.; Tattersall, A. (2004) Stress in Social Services: Mental Well-being, Constraints and Job Satisfaction. British Journal of Social Work, 34, 735-746. DOI:10.1093/ bjsw/bch088

Collins, S. (2008) Statutory Social Workers: Stress, Job Satisfaction, Coping, Social Support and Individual Differences. British Journal of Social Work, 38, 1173-1193. DOI:10.1093/ bjsw/bcm047

Conrad, D. \& Kellar-Guenther, Y. (2006) Compassion Fatigue, Burnout and Compassion Satisfaction among Colorado Child Protection Workers. Child Abuse and Neglect, 30, 1071-1080. DOI: 10.1016/j.chiabu.2006.03.009

Daniels, K. (2000) Measures of Five Aspects of Affective Well-being at Work. Human Relations, 53(2), 275-294.

Danna, K. \& Griffin, R.W. (1999) Health and Well-Being in the Workplace: A Review and Synthesis of the Literature. Journal of Management, 25(3), 357-384.

de Jonge, J. \& Schaufeli, W.B. (1998) Job Characteristics and Employee Well-being: A Test of Warr's Vitamin Model in Health Care Workers using Structural Equation Modelling. Journal of Organizational Behavior, 19, 387-407. DOI:10.1002/(SICI)10991379(199807) 19:4<3

Decker, J.; Bailey, T.L. \& Westergaard, N. (2002) Burnout among Childcare Workers. Residential Treatment for Children and Youth, 19(4), 61-77.

Demerouti, E; Bakker, A.B.; Nachreiner, F. \& Schaufeli, W.B. (2001) The Job Demands-Resources Model of Burnout. Journal of Applied Psychology, 86(3), 499-512. DOI:10.1037//00219010863499

Dill, K. (2007) Impact of Stressors on Front-Line Child Welfare Supervisors. The Clinical Supervisor, 26(1/2), 177-193. DOI: 10.1300/J001v26n01.12

Elpers, K. \& Westhuis, D. (2008) Organizational Leadership and Its Impact on Social Workers' Job Satisfaction: A National Study. Administration in Social Work, 32(3), 26-43. DOI: 10.1080/0364310080192239

Evans, S.; Huxley, P.; Gately, C.; Webber, M.; Mears, A.; Pajak, J.; Kendall, K. \& Katona, C. (2006) Mental Health, Burnout and Job Satisfaction Among Mental Health Social Workers in England and Wales. British Journal of Psychiatry, 188, 75-80. DOI:10.1192/ bjp.188.1.75

Farmer, R.; Monahan, L. \& Hekeler, R. (1984) Stress Management for Human Services. Sage Publications, London.

Figley, C. (2002) Compassion Fatigue: Psychotherapists' Chronic Lack of Self Care. Psychotherapy in Practice, 58(11), 1433-1441.

Freudenberger, H. (1974) Staff Burn-Out. Journal of Social Issues, 30(1), 159-165.

Gillespie, D. (ed.) (1986). Burnout among Social Workers. The Harworth Press, London.

Guest, D; Conway, N. (2009) Health and Well-Being: The Role of the Psychological Contract. In: International Handbook of Work and Health Psychology (eds C.L. Cooper; J. Campbell Quick \& M.J. Schabracq), pp. 9-24. Wiley \& Blackwell, Chichester.

Horwitz, M. (1998) Social Worker Trauma: Building Resilience in Child Protection Social Workers. Smith College Studies in Social Work, 68(3), 363-377.

Kanter, J. (2007) Compassion Fatigue and Secondary Traumatization: A Second Look. Clinical Social Work Journal, 35, 289-293. DOI:10.1007/s10615-007-0125-1

Kets de Vries, M.; Guillén Ramo, L. \& Krotov, K. (2009) Organizational Culture, Leadership, Change and Stress. In: International Handbook of Work and Health Psychology (eds C.L. Cooper; J. Campbell Quick \& M.J. Schabracq), pp. 411-426. Wiley \& Blackwell, Chichester.

Kim, H. \& Stoner, M. (2008) Burnout and Turnover Intention among Social Workers: Effects of Role Stress, Job Autonomy and Social Support. Administration in Social Work, 32(3), 5-25. DOI:10.1080/03643100801922357 
Knight, C. (2010) Indirect Trauma in the Field Practicum: Secondary Traumatic Stress, Vicarious Trauma, and Compassion Fatigue among Social Work Students and Their Field Instructors. The Journal of Baccalaureate Social Work, 15(1), 31-52.

Koeske, G.; Kirk, S.; Koeske, R. \& Rauktis, M.B. (1994) Measuring the Monday Blues: Validation of a Job Satisfaction Scale for the Human Services. Social Work Research, 18(1), 27-35.

Koeske, G. \& Kirk, S. (1995) The Effect of Characteristics of Human Service Workers on Subsequent Morale and Turnover. Administration in Social Work, 19(1), 15-31.

Lizano, E.L. \& Mor Barak, M.E. (2012) Workplace Demands and Resources as Antecedent of Job Burnout among Public Child Welfare Workers: A Longitudinal Study. Children and Youth Services Review, 34, 1769-1776. DOI:10.1016/j.childyouth.2012.02.006

Maslach, C. \& Jackson, S. (1981) The Measurement of Experienced Burnout. Journal of Occupational Behaviour, 2, 99-113.

Maslach, C.; Schaufeli, W.B. \& Leiter, M. (2001) Job Burnout. Annual Reviews Psychology, 52, 397-422. DOI: 10.1146/annurev.psych.52.1.397

McCarter, A.K. (2007) The Impact of Hopelessness and Hope on the Social Work Profession. Journal of Human Behaviour in the Social Environment, 15(4), 107-124. DOI:10.1300/ J137v15n04_07

Napoli, M. \& Bonifas, R. (2011) From Theory toward Empathic Self-Care: Creating a Mindful Classroom for Social Work Students. Social Work Education, 30(6), 635-649. DOI:1 $0.1080 / 02615479.2011 .586560$

Nelson, D.L. \& Simmons, B.L. (2011) Savoring Eustress while Coping with Distress: The Holistic Model of Stress. In: Handbook of Occupational Health Psychology (eds J. Campell Quick \& L.E. Tetrick), pp. 55-74. American Psychological Association, Washington, DC.

Nelson-Gardell, D. \& Harris, D. (2003) Childhood Abuse History, Secondary Traumatic stress, and Child welfare Workers. Child Welfare, 82(1), 5-26. DOI:0009-4021/2003/010005-22

Nissly, J.; Mor Barak, M. \& Levin, A. (2005) Stress, Social Support, and Workers' Intentions to Leave Their Jobs in Public Child Welfare. Administration in Social Work, 29(1), 79-100. DOI:10.1300/J147v9n01_06

Nuopponen, A. (2011) Methods of Concept Analysis-Tools for Systematic Concept Analysis. LSP Journal, 2(1), 4-15.

Radey, M. \& Figley, C. (2007) The Social Psychology of Compassion. Clinical Social Work Journal, 35, 207-214. DOI:10.1007/s10615-007-0087-3

Rauktis, M.E. \& Koeske, G. (1994) Maintaining Social Worker Morale: When Supportive Supervision Is not Enough. Administration in Social Work, 18(1), 39-60.

Rossrucker, K. (2008) Arbeitszufriedenheit und ibre Folgen in helfenden Berufen. [Job-Satisfaction and Its Consequences in Helping Professions] Logos Verlag, Heidelberg.

Ruch, G.; Turney, D. \& Ward, A. (eds) (2010) ‘Relationship-Based Social Work'. Jessica Kingsley Publishers, London.

Schaufeli, W.B.; Salanova, M.; González-Romá, V. \& Bakker, A.B. (2002) The Measurement of Engagement and Burnout: A Two Sample Confirmatory Factor Analytic Approach. Journal of Happiness Studies, 3, 71-92.

Schaufeli, W.B. \& Bakker, A.B. (2003) UWES Utrecht Work Engagement Scale. Preliminary Manual (Version 1, November 2003). Retrieved May 30, 2011, from Occupational Health Psychology Unit, Utrecht University, http:/www.schaufeli.com/

Schaufeli, W.B.; Bakker, A.B. (2004) Job Demands, Job Resources, and their Relationship with Burnout and Engagement: A Multi-sample Study. Journal of Organizational Behavior, 25, 293-315. DOI:10.1002/job.248

Schrapper, C. (1999) "Gute Arbeit machen" oder "die Arbeit gut machen"? Entwicklung und Gewährleistung von Qualitätsvorstellungen für die Arbeit im Allgemeinen Sozialen Dienst (ASD). ['Doing a good work' or 'doing the work well'? Development and warranty of 
quality for the work in social agencies] In: Qualität in der Jugendhilfe: Kriterien und Bewertungsmöglichkeiten [Quality in the child welfare service: Criteria and evaluation possibilities], (ed. Merchel, J.) Votum Verlag, Münster.

Sexton, L. (1999) Vicarious Traumatisation of Counsellors and Effects on Their Workplaces. British Journal of Guidance and Counselling, 27(3), 393-403.

Siebert, D.C. (2005) Personal and Occupational Factors in Burnout among Practicing Social Workers: Implications for Researchers, Practitioners, and Managers. Journal of Social Service Research, 32(2), 25-44. DOI:10.1300/J079v32n02_02

Söderfeld, M.; Söderfeld, B. \& Warg, L.E. (1995) Burnout in Social Work. Social Work, 40(5), 638-646.

Sprang, G.; Clarc, J. \& Whitt-Woosley, A. (2007) Compassion Fatigue, Compassion Satisfaction, and Burnout: Factors impacting a Professional's Quality of Life. Journal of Loss and Trauma, 12, 259-280. DOI:10.1080/15325020701238093

Sudbery, J. (2002) Key Features of Therapeutic Social Work: the Use of Relationship, Journal of Social Work Practice, 16(2) 149-162. DOI:10.1080/0265053022000033711

Tham, P. (2007) Why Are They Leaving? Factors Affecting Intention to Leave among Social Workers in Child Welfare. British Journal of Social Work, 37, 1225-1246. DOI:10.1093/ bjsw/bcl054

Tims, M.; Bakker, A.B. \& Derks, D. (2012) Development and Validation of the Job Crafting Scale. Journal of Vocational Behaviour, 80, 173-186. DOI:10.1016/j.jvb.2011.05.009

Tinline, G. \& Moss, B. (2009) Building Interventions to Improve Staff Well-Being. In: International Handbook of Work and Health Psychology (eds C.L. Cooper; J. Campbell Quick \& M.J. Schabracq), pp. 427-443. Wiley \& Blackwell, Chichester.

Ulrich, C.; O’Donnell, P.; Taylor, C.; Farrar, A.; Danis, M. \& Grady, C. (2007) Ethical Climate, Ethic Stress, and the Job Satisfaction of Nurses and Social Workers in the United States. Social Science and Medicine, 65, 1708-1719. DOI:10.1016/j.socscimed.2007.05.050

van Hook, M. \& Rothenberg, M. (2009) Quality of Life and Compassion Satisfaction/ Fatigue and Burnout in Child Welfare Workers: A Study of the Child Welfare Workers in Community Based Care Organizations in Central Florida. Social Work \& Christianity, 36(1), 36-54.

van Horn, J.; Taris, T.W. \& Schaufeli, W.B. (2004) The Structure of Occupational Well-being: A Study Among Dutch Teachers. Journal of Occupational and Organizational Psychology, 77, 365-375.

van Steenbergen, E.F. \& Ellemers, N. (2009) Is Managing the Work-Family Interface Worthwhile? Benefits for Employee Health and Performance. Journal of Organizational Behavior, 30, 617-642. DOI:10.1002/job.569

Warr, P. \& Routledge, T. (1969) An Opinion Scale for the Study of Manager's Job Satisfaction. Journal of Occupational Psychology, 43, 95-109.

Warr, P.; Cook, J. \& Wall, T. (1979) Scales for the Measurement of Some Work Attitudes and Aspects of Psychological Well-being. Journal of Occupational Psychology, 52, 129-148.

Weaver, D.; Chang, J.; Clark, S. \& Rhee, S. (2007) Keeping Public Child Welfare Workers on the Job. Administration in Social Work, 31(2), 5-25. DOI:10.1300/J147v31n02_02

Winfield, H.R. \& Barlow, J.A. (1995) Client and Worker Satisfaction in a Child Protection Agency. Child Abuse and Neglect, 19(8), 897-905.

Wrzesniewski, A. \& Dutton, J.E. (2001) Crafting a Job: Revisioning Employees as Active Crafters of their Work, Academy of Management Review, 26(2), 179-201. 